\title{
POR UMA EDUCAÇÃO CRÍTICA E PARTICIPATIVA [FREI BETTO]
}

\author{
DOI: http://doi.org/10.9771/gmed.v13i3.45839
}

Mike Ceriani de Oliveira Gomes ${ }^{1}$

Título: Por uma educação crítica e participativa

Autor: Frei Betto

Cidade e editora: Rio de Janeiro, Anfiteatro

Ano de publicação: 2018

Páginas: 288

A obra Por uma educação crítica e participativa, de autoria do frade dominicano e jornalista mineiro Frei Betto, conta com uma linguagem didática para expor os pensamentos deste escritor e educador popular acerca da educação, tendo em cada capítulo muito clara a expressão de um crítico que avalia o sistema educacional formal por uma orientação do socialismo utópico e da teologia da libertação. Dividido em sete capítulos, o livro toma em cada um dos seis primeiros um tema específico que é discorrido pelo autor, não ocorrendo no último capítulo, em que são fragmentados temas diversos, sem uma orientação central. A partir de cada tema, há uma subdivisão em tópicos redigidos de forma sucinta, de modo a não tornar a leitura cansativa e nem carente de informações.

O autor abre o primeiro capítulo, Escola e Família, de modo a colocar logo no primeiro tópico, intitulado A Escola dos Meus Sonhos, seu entendimento do que seria um modelo curricular e pedagógico eficaz para o sistema de ensino formal. Tal modelo, em contraposição à escola que não dialoga com a realidade das educandas e dos educandos, negando também o caráter político da educação, mostra o anseio do autor por uma educação popular, ainda que não o tenha explicitado logo no início com essas palavras, deixando claro o que verdadeiramente se deve entender por educação popular.

$\mathrm{Na}$ escola dos meus sonhos, os alunos aprendem a cozinhar, costurar, consertar eletrodomésticos, fazer pequenos reparos de eletricidade e instalações hidráulicas, conhecer mecânica de automóvel e geladeira, e noções de construção civil. Trabalham em horta, marcenaria e oficinas de escultura, desenho, pintura e música. Cantam no coro e tocam na orquestra.

Uma semana ao ano integram-se, na cidade, ao trabalho de lixeiros, enfermeiros, carteiros, guardas de trânsito, policiais, repórteres, feirantes, garçons e cozinheiros profissionais. Assim, aprendem como a cidade se articula por baixo, mergulhando em suas conexões subterrâneas que, à superfície, nos asseguram limpeza urbana, socorro de saúde, segurança, informação e alimentação.

Não há temas tabus. Todas as situações-limite da vida são tratadas com abertura e profundidade: dor, perda, falência, parto, morte, enfermidade, sexualidade e espiritualidade. Ali os alunos aprendem o texto dentro do contexto: a matemática busca exemplos na corrupção dos políticos e nos leilões das privatizações; o português, na fala dos apresentadores de TV e nos textos de jornais; a geografia, nos suplementos de turismo e nos conflitos internacionais, a física, nas corridas de Fórmula 1 e nas pesquisas dos supertelescópios; a química, na qualidade dos cosméticos e na culinária; a história, na violência de policiais a cidadãos, para mostrar os antecedentes na relação colonizadoresíndios, senhores-escravos, Exército-Canudos etc. 
$\mathrm{Na}$ escola dos meus sonhos, a interdisciplinaridade permite que os professores de biologia e educação física se complementem; a multidisciplinaridade faz com que a história dos livros seja estudada a partir da análise de textos bíblicos; a transdisciplinaridade introduz aulas de meditação e dança, e associa a história da arte à história das ideologias e das expressões litúrgicas.

$\mathrm{Na}$ escola dos meus sonhos os professores são obrigados a fazer periódicos treinamentos e cursos de capacitação, e apenas admitidos se, além da competência, comungam com os princípios fundamentais das propostas pedagógica e didática. Porque é uma escola com ideologia, visão de mundo e perfil definido sobre o que são democracia e cidadania. Essa escola não forma consumidores, mas cidadãos.

Ela não briga com a TV, mas leva-a para a sala de aula: são exibidos vídeos de anúncios e programas e, em seguida, analisados criticamente. A publicidade do iogurte é debatida; o produto, adquirido; sua química, analisada e comparada com a fórmula declarada pelo fabricante; as incompatibilidades denunciadas, bem como os fatores porventura nocivos à saúde. O programa de auditório de domingo é dissecado: a proposta de vida subjacente; a visão de felicidade; a relação animador-plateia; os tabus e preconceitos reforçados etc. Em suma, não se ignora a realidade, muda-se a ótica de encará-la.

Há uma integração entre escola, família e sociedade. A Política, com P maiúsculo, é disciplina obrigatória. As eleições para o grêmio ou diretório estudantil são levadas a sério, e um mês por ano setores não vitais da instituição são administrados pelos próprios alunos. Os políticos e candidatos são convidados para debates e seus discursos analisados e comparados às suas práticas. (p. 13-15)

Um destaque a este trecho do primeiro tópico faz-se importante visto que, além de sintetizar de forma concisa um modelo escolar ansiado por um educador popular (em específico um teólogo da libertação), também é tomado como ponto de partida para suas críticas aos agentes antagônicos a esse modelo, além dos desafios a serem tomados para tal resultado. O capítulo tem sequência expressando sobre como, na visão do autor, a educação deve proceder nas relações familiares, na formação da criança enquanto exposta a perigos de uma mídia desenfreada (mídia a ser por muitas vezes criticada pelo autor no decorrer da obra) e ao discurso moralista da sociedade de classes.

No segundo capítulo, Educação e Mídia, o autor retoma com maior profundidade algumas das breves críticas tecidas à mídia. Enquanto um tópico do primeiro capítulo expressava sua preocupação para com a televisão enquanto formadora de indivíduos consumistas, mediante anúncios publicitários apelativos e, ao mesmo tempo, livres de censura do poder público, o segundo capítulo apresenta dados qualitativos e quantitativos que permitem a pesquisadores e profissionais da saúde mental concluir a nocividade da exposição da criança à TV, cada vez mais frequente, podendo assim potencializar aspectos de perda da capacidade de socialização, carência afetiva sanada paliativamente pelo consumo de produtos de anúncios publicitários e o gradativo aumento da ansiedade e das frustrações muitas vezes expressadas em nostalgias. Deixando mais claro seu diagnóstico pessoal quanto a essa realidade, o autor responsabiliza a progressão da agenda neoliberal, na qual é um imperativo instigar o indivíduo à busca pelo status, que é atingido mediante o consumo, justificando assim os investimentos bilionários em publicidade televisiva. A contraposição a essa lógica se daria, portanto, na escola, com o resgate a valores éticos e do pensamento coletivista. $\mathrm{O}$ autor não se incomoda, em nenhum momento, ao expressar seu interesse pela religiosidade enquanto ferramenta para resgate desses valores, contudo, ainda que expressando sua preferência pelo catolicismo, reconhece quaisquer outras manifestações como fundamentalmente importantes para atingir uma finalidade comumente almejada: a desconstrução da alienação midiática. 
O terceiro capítulo, intitulado Para Que Serve a Educação?, é discorrido pelo autor de modo a explicitar a educação enquanto ferramenta para diferentes fins de acordo com o grupo de interesses que se apropria da mesma. Nesse capítulo fica muito clara a crítica à educação concebida em seio escolar, como tal modelo contribui para o avanço da agenda neoliberal. Evidenciando ainda mais sua influência a partir da literatura de Paulo Freire (a quem o autor também dedica a obra, junto a Lauro de Oliveira Lima, Darcy Ribeiro e Rubem Alves), o autor recorda o modelo "bancário" do sistema de educação formal vigente no Brasil, modelo acrítico que consiste na transferência de conteúdo ao educando e à educanda que recebe e quando muito aplica em seu cotidiano para finalidades cada vez mais mesquinhas, sendo esta uma lógica determinada pelo neoliberalismo. O autor retoma o papel da mídia nesse processo e, igualmente, o papel da educadora e do educador que se contrapõem a tal lógica, tomando a mídia não como uma inimiga a ser desconstruída pelo mesmo modelo acrítico e bancário com o qual se faz educação no ambiente de ensino formal, mas como objeto pedagógico a ser debatido no espaço de formação. Nessa direção, o autor também reforça a necessidade da modernização da abordagem educativa para uma efetiva contraposição aos problemas enfrentados na atualidade.

A menção ao interesse neoliberal na educação e a crítica ao modelo de educação bancária dão ensejo a questões importantes tratadas no capítulo quatro, Temas Polêmicos - Desafios à Educação, em que o autor inicia com uma denúncia ao projeto de lei Escola Sem Partido, idealizado pelo Movimento Escola Sem Partido e sua demanda por uma suposta neutralidade política em ambiente escolar. Tomando por vezes o trabalho realizado em escolas confessionais, o autor frequentemente recorre à argumentação da importância da abertura ao diálogo para diversos temas, muitos dos quais ainda tabus, justificando ser esta uma alternativa de aproximação da escola com a realidade do público ao qual ela atende. São expostas, desta forma, adversidades oriundas da falta de abertura ao diálogo e honestidade em nome de um puritanismo conservador, tais como a gravidez indesejada. Neste capítulo também é clarificado como a suposta neutralidade em ambiente educacional pode assumir caráter de manutenção do desconhecimento de princípios dos Direitos Humanos como o direito à vida e à liberdade, bem como sua forma de preservar a educanda e o educando alienados à propaganda televisiva e à ideologia neoliberal.

No quinto capítulo, Papel da Universidade, o autor é mais enfático em temas relacionados à formação do educador, sobretudo universitário, tanto em aspectos científicos quanto ideológicos, a fim de propiciar a aprendizagem ao educando e à educanda para o confronto com a realidade tal qual se apresenta. Parcialmente, pode-se compreender é idealizado um modelo de universidade similar ao modelo de escola descrito no primeiro tópico do primeiro capítulo desta obra. Este nível de ensino também é tratado como um campo tomado por agentes neoliberais a partir do momento em que se sustenta a ideia da formação do educando e da educanda meramente para o atendimento a anseios de cunho individualista. De acordo com o autor, à universidade, cada vez mais comprometida a um modelo comercial, lhe falta a capacidade de formar sujeitos intelectuais para que questionem não apenas dilemas conjunturais, mas toda a estrutura sustentada pelo neoliberalismo. É proposto então um modelo que, consigo, envolva a formação moral, formação essa que o autor justifica ter faltado a grandes mentes da academia que em uso meramente de suas competências técnicas protagonizaram grandes atrocidades, tais como a criação de bombas atômicas. Em 
diversos momentos deste capítulo o autor reforça a importância da extensão universitária, formando cidadãs e cidadãos não para ostentarem um ego que acompanha o diploma de ensino superior, mas para relacionarem-se com a comunidade e com o mundo, tal como ocorre em Cuba com o "Programa Mais Médicos", para mencionar um exemplo.

O sexto capítulo, Educação Popular - O Que É, Como Faẓer, é o mais extenso da obra, trazendo de volta alguns dos temas debatidos até então e complementando sua visão sobre educação popular em diversos aspectos e contextos. Logo no primeiro tópico, o autor menciona sua relação pessoal com Paulo Freire e o legado de Freire no desenvolvimento da educação popular com o método ação-reflexão-ação. Esta mesma referência é utilizada pelo autor para criticar a linguagem extremamente acadêmica que demasiados educadores e comunicadores de esquerda utilizam em uma vã tentativa de se acercarem às massas populares. O autor reforça que, sendo um processo educativo que se dá pela troca, na educação popular, libertadora que coloca o sujeito como protagonista de sua história, não há alguém que ensina e alguém que aprende, há um conhecimento e uma formação crítica, construídos a partir da dialética vivida pelas situações-problema dos envolvidos. Desta maneira, as experiências de vida e os conhecimentos de membros das classes populares são tomados como ponto de partida para que explorem um tema mais amplo. É relatada uma experiência em que o autor coloca um grupo de operários frente a uma linha de produção de caminhões e, por relacionarem o quanto ganham e qual é o valor do produto que produzem para o mercado, passam a compreender a teoria da mais valia.

Ainda no sexto capítulo, o autor dedica-se muito a discorrer o perfil do educador popular e da educadora popular, em alguns momentos, por suas intenções formuladas em determinações históricofamiliares, ou seja, o ponto de partida que faz do sujeito educador popular, sempre tendo claro que esse ensejo pode definir seus objetivos em curto e longo prazo. Contrariando o ditado popular "faça o que eu digo, mas não faça o que eu faço", o autor se reveste de um pensamento genuinamente freireano ao defender que a educadora popular e o educador popular precisam assumir-se como testemunhas do que pregam e das mudanças que almejam, e isso implica não só despirem-se do discurso fatalista neoliberal, mas também estarem na luta do povo, não o fazerem para o povo ou pelo povo, mas com o povo, em um protagonismo construído em conjunto e onde a educadora e o educador permitam educarem-se enquanto educam. A análise de perfil também se faz útil ao avaliar indivíduos com outros interesses que se valem da luta das classes populares para a obtenção de anseios individuais, tais como agentes políticos que não têm sua luta pautada na emancipação das classes oprimidas, buscando nessas classes apenas capital eleitoral.

O autor é enfático ao tratar a formação e a abordagem da educadora e do educador popular não apenas pela intenção que os leva a tal compromisso, mas também pelo método utilizado, pela linguagem que utilizam ao se aproximarem de educandos. Muitas críticas são reservadas ao modelo de alienação culturalmente propagado no sistema de ensino formal, em que educandos são tratados como seres não dotados de nenhum saber, tampouco de qualquer capacidade de aprendizagem. No modelo tradicional, a informação é transmitida a todos os participantes, de modo que não participem da construção do saber e se limitem à mera memorização. Não se trata do modelo de educação popular, do povo e com o povo, mas de um modelo de alienação, paralelo ao modelo libertador. A educação popular não nega a capacidade de 
aprender, não se limita ao apreender (conteúdo já decodificado) e não conta com um detentor único do conhecimento, mas de um bom ouvinte, capaz não apenas de transformar, mas de ser transformado pelas estórias e saberes populares.

Neste mesmo capítulo, o autor também traz críticas ao currículo da escola formal, sendo ele elaborado a partir de interesses que não são populares. A demanda por uma educação popular segue, então, justificada pelo alinhamento do conteúdo disseminado na escola às necessidades do cotidiano da educanda e do educando. É reforçado que a formação acompanha o interesse de quem gere o sistema, portanto, se a escola é gerida por agentes neoliberais, esta é uma educação gerida para a propagação da agenda neoliberal. O autor utiliza como exemplo também uma escola protestante, que logo no ato da matrícula informa pais e responsáveis do caráter confessional no processo formativo. Seguindo esta direção, o autor propõe que, ao adentrar o sistema de ensino formal, a educação popular também deve ser gerida e clara quanto aos seus objetivos, sobretudo no que tange à formação. Desta maneira, o currículo deve ser elaborado para tal formação e "[...] o aluno será levado a um assentamento dos sem-terra para conhecer o dia a dia daquelas famílias de trabalhadores, visitará um acampamento de moradores sem-teto e fará estágio em uma ONG que trabalha com proteção ambiental” (p. 230). Neste modelo, assim como em escolas confessionais, o consentimento é primordial para a boa relação entre família e escola.

Fugindo à regra de elaboração de escrita a partir de um tema central, no sétimo e último capítulo, intitulado Textos Educativos (Para Reflexão de Alunos, Professores e Professoras), o autor pauta os tópicos em assuntos diversos, alguns dos quais convidam a leitora e o leitor a reflexões no que tange às relações do indivíduo com a sociedade e com o meio ambiente, sendo alguns deles atrativos para eventuais discussões educativas em grupo no ambiente escolar. Trata-se um capítulo em que o autor brevemente retoma sua crítica ao consumismo exacerbado e a alienação promovida a partir de aparatos midiáticos. Com um exemplar exercício proposto para a autocrítica, o autor também sugere uma avaliação do discurso moralista que frequentemente é empregado para condenar grupos marginalizados pela sociedade, mas que, de alguma maneira, representam diversas características que bem descrevem o emissor do discurso moralista. Naturalmente, alguns dos textos deste capítulo buscam provocar um incômodo necessário para a autocrítica e para o amadurecimento do pensamento em relação a diversos temas, sobretudo os mais polêmicos.

Esta não é uma obra acadêmica, pois não se vale de uma metodologia acadêmica em sua elaboração. Alguns dos dados apresentados, como estudos de psicólogos, neurologistas e profissionais da saúde mental em geral não são referenciados seguindo modelos de normas científicas. Contudo, a clareza e a riqueza argumentativa do autor ao tratar os principais assuntos desta obra podem caracterizá-la como um material de interesse acadêmico. Há aspectos que não podem fugir a críticas, a exemplo de um saudosismo demasiado que, em alguns momentos, é notório que se mostra como abordagem didática ao expressar como muitos desafios no campo educacional alteraram à medida que alterou a conjuntura do país, e isso fica bem explicado quando o autor trata os processos midiáticos em seu tempo e na atualidade. Alguns pequenos tópicos de cada capítulo, sobretudo nos quatro primeiros, algumas vezes parecem fugir do principal, mas trata-se apenas de informações adicionais aleatórias, não reduzindo, de nenhuma maneira, a qualidade da 
obra. De maneira geral, esta obra pode ser muito boa também para discussão em grupos de pesquisas que se dedicam a estudar a educação crítica, democrática e popular.

\section{Referências:}

BETTO, F. Por uma educação crítica e participativa. Rio de Janeiro: Anfiteatro, 2018.

\section{Notas}

${ }^{1}$ Especialista em Metodologia do Ensino da Língua Inglesa pelo Instituto Pedagógico de Minas Gerais (Ipemig). Mestrando em Educação pela Faculdade de Filosofia e Ciências (FFC) da Universidade Estadual Paulista Júlio de Mesquita Filho (Unesp/Marília). Membro do grupo de pesquisa Organizações e Democracia (Unesp/Marília) - dgp.cnpq.br/dgp/espelhogrupo/0817566490116925.

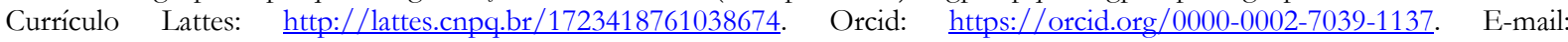
mikegd1@hotmail.com.

Recebido em: 25 ago. 2021

Aprovado em: 27 out. 2021 